\title{
Antiviral activity of fungi of the Novosibirsk Region: Pleurotus ostreatus and $P$. pulmonarius (Review)
}

\author{
Vyacheslav Vlasenko ${ }^{1, *}$, and Anastasia Vlasenko \\ ${ }^{1}$ Central Siberian Botanical Garden SB RAS, 630090 Zolotodolinskaya st., 101, Novosibirsk, Russia
}

\begin{abstract}
The article reviews of antiviral properties of two species of fungi from the Novosibirsk Region of the genus Pleurotus. Fruit bodies and cultivated mycelium of Pleurotus ostreatus and P. pulmonarius are a promising source of extracts with polysaccharides, possessing antiviral and anti-cancer properties.
\end{abstract}

\section{Introduction}

Pleurotus ostreatus and P. pulmonarius are saprotrophic wood-inhabiting basidiomycetes of the Pleurotaceae family (figure. 1).
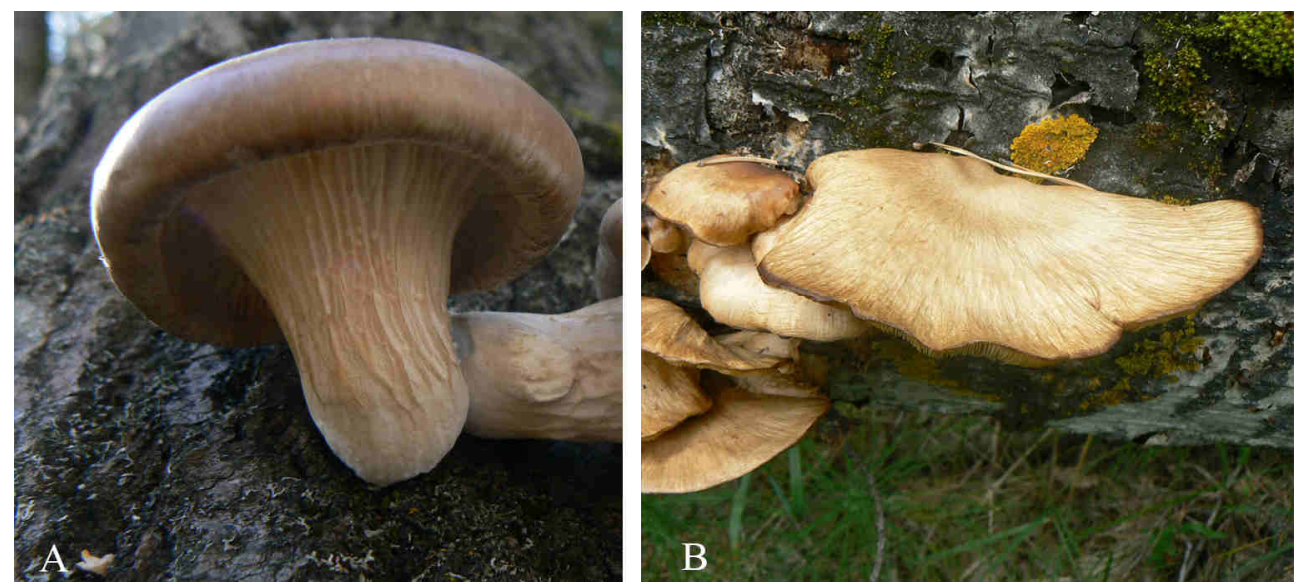

Fig. 1. Pleurotus ostreatus (A) and P. pulmonarius (B) on various substrates of the Novosibirsk Region.

These mushrooms are edible, their fruit bodies are a valuable dietary product. Oyster mushrooms are cultivated on commercially as a food product. In Novosibirsk Region, in

\footnotetext{
*Corresponding author: vlasenkomyces@mail.ru
} 
nature, these species are widespread, they grows on many species of woody plants, most often deciduous, but can also grow on coniferous plants.

$P$. ostreatus and $P$. pulmonarius have medicinal properties, the polysaccharides contained in them exhibit a high antioxidant, antitumor, immunomodulatory, antiviral and other effects [5].

The aim of the study is to review the literature on the antiviral activity of extracts from fruiting bodies and mycelial cultures of $P$. ostreatus and $P$. pulmonarius. We plan to study the dependence of the antiviral activity of the fungi of the genus Pleurotus on their strain diversity.

\section{Materials and methods}

Antiviral activity has been identified in many agaricoid and polyporoid fungi. In Russia, the antiviral activity of wood-inhabiting basidiomycetes of Western Siberia was studied by us together with the employees of the State Research Center of Virology and Biotechnology VECTOR (Koltsovo, Novosibirsk Region) [8, 15, 17].

\section{Results and Discussion}

The antiviral properties of fungi began to be studied in the second half of the 20th century. For the first time in 1979, data were obtained on the antiviral activity of the extract from Lentinula edodes [13]. In 1969, the antitumor activity of a polysaccharide extracted from the fruit body of P. ostreatus [20].

Polysaccharides of oyster mushrooms were first isolated from $P$. ostreatus. It was an insoluble polysaccharide Pleuran [7], commercial name Imunoglukan ${ }^{\circledR}$. It possesses immunomodulating properties that make the body more resistant to infections and cancer [10] and has other properties. It was found that polysaccharides possess antitumor activity [1].

The antiviral properties of aqueous and methanol extracts of $P$. ostreatus were evaluated against herpes simplex virus type 1 (HSV-1). Antiviral activity correlates with the betaglucans present in the polysaccharide fraction, which showed higher antiviral activity than aqueous extracts [12].

Water extracts with polysaccharides $P$. ostreatus and $P$. pulmonarius were active against the herpes simplex virus of the second type. The antiviral activity of water extracts of fungi is associated with the presence of polysaccharides and increases with increasing concentration of polysaccharides [2].

Extracts with polysaccharides obtained from water extracts from the genus Pleurotus completely suppress the infectious activity of at least 1000 TCID50 of the West Nile virus [11].

Aquatic extracts of $P$. pulmonarius fruiting bodies showed high activity against influenza viruses $(6.06 \pm 0.18 \mathrm{lg}$ for $\mathrm{H} 5 \mathrm{~N} 1$ and $5.73 \pm 0.14 \mathrm{lg}$ for H3N2) [6].

The antiviral activity of the in vitro mycelium of higher fungi against influenza A virus (serotype H1N1) and herpes simplex virus type 2 (HSV-2), strain BH was investigated. $P$. ostreatus inhibited the propagation of the influenza A / FM / 1/47 (H1N1) virus strain in MDCK cells that reduce the infectious titer by 2.0-6.0 lg ID50. It was determined that $P$. ostreatus is effective against HSH-2 strain BH in RK-13 cells with similar levels of inhibition as for influenza [9].

Ubiquitin-like glycoprotein was isolated from $P$. ostreatus, which inhibited the development of the human immunodeficiency virus [18]. 
It was found that the purified lectins of $P$. ostreatus as an adjuvant $(1 \mathrm{mg} / \mathrm{ml})$ also enhance the immunogenicity of the hepatitis B DNA vaccine [3].

\section{Conclusions}

Many polysaccharides exhibiting antiviral effects also possess antitumor properties [16, 19]. Data on the antitumor and antiviral activity of the same species of fungi indicate a correlation between these properties [14]. The role of extracts obtained from basidiomycetes can only increase, because in addition to the prevention and treatment of viral infections, polysaccharides and other metabolites of fungi will contribute to the prevention of types of cancer that have a viral etiology [4].

The reported research was funded by Russian Foundation for Basic Research and the government of the Novosibirsk Region of the Russian Federation, grant № 18-44-543018.

\section{References}

1. P. Bobek, E. Ginter, L. Kuniak, J. Babala, M. Jurcovicova, L. Ozdín, J. Cerven, Nutritio 7 , 105-108 (1991)

2. G. Chihara, J. Hamuro, Y.Y. Maeda, Y. Arai, F. Fukuoka, Cancer Res. 30, 2776-2781 (1970)

3. W. Gao, Y. Sun, S. Chen, J. Zhang, J. Kang, Y. Wang, H. Wang, G. Xia, Q. Liu, Y. Kang, Vaccine 31, 2273-2280 (2013)

4. V.E. Gurtsevich, The Russian Therapeutic Journal 7, 8 (2008) (in Russian)

5. I.A. Gorbunova, V.A. Vlasenko, T.V. Teplyakova, T.A. Kosogova, I.N. Mikhaylovskaya, Coniferous of boreal zone 26, 12-21 (2009) (in Russian)

6. A.S. Kabanov, T.A. Kosogova, L.N. Shishkina, T.V. Teplyakova, M.O. Skarnovich, N. A. Mazurkova, L.I. Puchkova, E.M. Malkova, E.A. Stavskiy, I.G Drozdov, Journal of Microbiology, Epidemiology and Immunology 1, 40-43 (2011) (in Russian)

7. S. Karacsonyi, L. Kuniak, Carbohydrate Polymers 24, 107-111 (1994)

8. N.E. Kostina, Zh.B. Ibragimova, M.A. Protsenko, E.V. Makarevich, M.A. Skarnovich, E.I. Philippova, I.A. Gorbunova, V.A. Vlasenko, G.P. Troschkova, N.A. Mazurkova, L.N. Schischkina, Modern problems of science and education 3 (2013) (in Russian)

9. T. Krupodorova, S. Rybalko, V. Barshteyn, Virol Sin. 29, 284-190 (2014)

10. N.R. Di Luzio, Springer Seminars in Immunopathology 8, 387-400 (1985)

11. I.A. Razumov, T.A. Kosogova, E.I. Kazachinskaya, L.I. Puchkova, N.S. Shcherbakova, I.A. Gorbunova, I.N. Mikhailovskaya, V.B. Loktev, T.V. Teplyakova, Antibiotics and Chemotherapy 55, 14-18. (2010) (in Russian)

12. S. Santoyo, A.C. Ramírez-Anguiano, L. Aldars-García, G. Reglero, C. Soler-Rivas, Journal of food and nutrition research 51, 225-235 (2012)

13. M. Takehara, K. Kuida, K. Mori, Arch Virol. 59, 269-374, (1979)

14. T.V. Teplyakova, T.A. Kosogova, Higher Fungi of Western Siberia as Promising Objects for Drug Production Biotechnology, 298 (2014) (in Russian)

15. T.V. Teplyakova, N.V. Psurtseva, T.A. Kosogova, N.A. Mazurkova, V.A. Khanin, V.A. Vlasenko, Int. J. of Med. Mushrooms 14,37-45 (2012) 
16. S. Tochikura, Med. Microbiol. Immunol. 177, 235-244 (1988)

17. V.A. Vlasenko, T.V. Teplyakova, N.A. Mazurkova, T.A. Kosogova, A.V. Bardaschova, N.V. Psurtseva, Bulletin of the Altai State Agrarian University 90, 29-31 (2012) (in Russian)

18. H.X. Wang, T.B. Ng, Life Science 68, 2151-2158 (2001)

19. S.P. Wasser, A.L. Weis, Int. J. of Med. Mushrooms 1, 31-62, (1999)

20. T. Watanabe, Nippon Rinsho 27, 1759-1761 (1969) 